\section{Josué de Castro e as metamorfoses da fome no Brasil, 1932-1946}

\section{Josué de Castro and the metamorphoses of hunger in Brazil, 1932-1946}

Adriana Salay Leme ${ }^{i}$

Doutoranda, História Social/Universidade de São Paulo. São Paulo - SP - Brasil

orcid.org/0000-0003-3608-5766

adrianasalay@gmail.com

Recebido em 1 abr. 2020.

Aprovado em 30 nov. 2020.
LEME, Adriana Salay. Josué de Castro e as metamorfoses da fome no Brasil, 1932-1946. História, Ciências, Saúde Manguinhos, Rio de Janeiro, v.28, n.4, out.-dez. 2021, p.1115-1135.

\section{Resumo}

O termo fome, apesar de também significar uma sensação biológica, é um conceito multifacetado e historicamente colocado. Assim como outros, ele se transforma conforme a mudança da sociedade na qual está inserido. Este artigo examina, por meio das discussões propostas por Josué de Castro e sua inserção social, as representações da fome entre 1932 e 1946, ano no qual esse autor lançou seu livro Geografia da fome. A proposta é observar o espaço público letrado - literatura, imprensa de grande circulação e discussões científicas - para analisar como a fome era entendida nesse período e como Josué de Castro se inseriu nesse debate.

Palavras-chave: fome; Josué de Castro (1908-1973); nutrição; alimentação.

\section{Abstract}

The term hunger, despite also meaning a biological sensation, is a multifaceted, historically specific concept. Like others, it transforms along with changes in society. This article examines, through the discussions proposed by Josué de Castro and its social context, the representations of hunger between 1932 and 1946, the year in which Castro published his book The Geography of Hunger. The objective is to observe the literate public space - literature, mainstream press and scientific discussions - to analyze how hunger was understood during this period and how Josué de Castro took part in this debate.

Keywords: hunger; Josué de Castro (19081973); nutrition; food. 
$\mathrm{Pa}$ ara apreender as diferentes formas de fome é preciso introduzir uma distinção entre a fome instintiva e a fome como condição. A língua inglesa pode nos auxiliar com a diferenciação entre hunger, starvation e famine. Por hunger, entende-se a fome biológica, momentânea. O organismo necessita de calorias e manda uma mensagem ao cérebro pedindo comida - é uma sensação. Os ricos podem sentir fome tanto quanto os pobres. Starvation é o aumento dessa condição de fome, que pode ser individual ou coletiva, até um ponto crítico. Uma pessoa perdida no deserto pode morrer por starvation, mas isso não implica famine. Por famine entende-se a incapacidade de um grupo social de se alimentar por um período e por falta de acesso ao alimento em quantidade mínima para a manutenção da condição de uma vida saudável. É uma escassez de alimento coletiva. Isso quer dizer que, quando há famine, necessariamente há starvation, com mortes provocadas por ela e por doenças associadas, mas o oposto não é verdadeiro. Nesse caso, se um indivíduo sentir fome, será incapaz de aplacá-la porque não tem acesso ao alimento (Devereux, 1993).

Quando pensamos em famine e starvation, fazemos facilmente a ligação com crise. Thomas Keneally (2011), autor do livro Three famines, estava preocupado em analisar grandes crises de fome: na Irlanda, iniciada em 1845; em Bengal, em 1943-1944; e, por fim, na Etiópia, nos anos 1970 e 1980. Essa ligação entre fome e crise está historicamente colocada há muito tempo. Escritos medievais, por exemplo, aplicavam o conceito de fome ligado à crise ${ }^{1}$ (Silva, 2017).

Hoje, entretanto, vemos inúmeras discussões sobre fome com abordagens estruturais que apontam a condição de fome em uma população no curso regular dos acontecimentos, e não em uma situação excepcional. Segundo parte da literatura sobre o tema, atualmente há um interesse menor nos acontecimentos esporádicos, e os olhos e as ajudas humanitárias se voltaram para problemas endêmicos. A classificação do fenômeno da fome como pertinente a crises ou estruturas não é, contudo, matéria de consenso (Howe, Devereux, 2004).

Esse alargamento do olhar do evento para a estrutura se deu entre a segunda metade do século XIX e a primeira metade do século XX e já foi examinado na Inglaterra (Vernon, 2007). Esse enfoque, porém, ainda não existe sobre o contexto nacional. Alguns escritos passam pelo tema (Lima, 2000; Tobelem, 1974), mas a história do conceito da fome no Brasil, ou seja, como se dá a dinâmica interna em face dos debates internacionais com um escopo mais amplo de análise, ainda é um trabalho a se fazer.

Neste artigo, parte-se do princípio de que os debates nacionais, apesar de estarem ancorados em uma discussão internacional sobre alimentação e sua deficiência, têm suas especificidades: a primeira é a cronologia dos fatos, pela localização periférica do Brasil nas discussões científicas ocidentais, que adquire uma datação específica. A segunda é ser o Brasil um lugar de fome, ou seja, um país onde a fome marcou, e marca, uma parcela importante da população e dos processos históricos. Esse segundo ponto vai ser fundamental para as produções nacionais e o lugar em que vai se colocar a figura de destaque desse contexto brasileiro: Josué de Castro.

Josué Apolônio de Castro, nascido em Recife, em 1908, e morto em Paris, em 1973, é reconhecido por seus estudos sobre a fome e por sua participação em organizações de combate a ela, tendo sido presidente do conselho da Organização das Nações Unidas para Agricultura e Alimentação (FAO) e da Associação Mundial de Luta contra a Fome. Castro 
foi um intelectual e professor ativo, fosse ministrando aulas na Faculdade de Medicina do Recife, na Universidade do Distrito Federal, na Universidade do Brasil, atual Universidade Federal do Rio de Janeiro, ou em instituições internacionais. Além do trânsito acadêmico, Castro manteve seu consultório no Recife e, mais tarde, no Rio de Janeiro, de 1930 até meados dos anos 1950. Foi formador e articulador de diferentes organizações durante o governo Getúlio Vargas e, em 1954, elegeu-se deputado federal por Pernambuco pelo Partido Trabalhista Brasileiro (PTB), sendo reeleito em 1958. Em 1962, renunciou ao mandato para ser embaixador do Brasil na Organização das Nações Unidas (ONU). Josué de Castro teve ampla circulação em diversas esferas da sociedade, como médico, literato, articulador político, professor universitário e cientista. Publicou diferentes obras que versam sobre o tema da alimentação no Brasil, mas sua consagração como profeta da fome se deu quando lançou, em 1946, o livro Geografia da fome, traduzido em diversas línguas.

O papel de Josué de Castro para a discussão sobre a fome é inegável, reconhecido nacional e internacionalmente. Dessa forma, este trabalho pretende se debruçar sobre a epistemologia da fome por meio de suas representações e da transformação do seu conceito entre 1932 e 1946, ano em que Castro publicou Geografia da fome, e mostrar que a contribuição do autor não reside em lançar um tema inédito, mas em vincular discussões que já estavam acontecendo naquele momento.

Diversos trabalhos já trataram de sua trajetória e da análise de sua obra. A começar por Alain Tobelem - Josué de Castro e a descoberta da fome -, lançado um ano após a morte de Castro. Nele, o autor diz: "Josué de Castro ..., desde a infância, assumiu o partido dos que têm fome, ... sentiu o ambiente de sua infância como um estímulo a partir do qual conhece a revolta" (Tobelem, 1974, p.33). Durante a década de 1980, uma série de eventos discutiu o autor, e, em 1992, Rosana Magalhães defendeu uma dissertação na Fiocruz com o título Fome no pensamento de Josué de Castro, que se tornará o livro Fome: uma (re) leitura de Josué de Castro (Magalhães, 1997), considerado o primeiro estudo sistemático brasileiro que se debruça sobre sua obra. A partir de então, foram feitos alguns trabalhos acadêmicos, ${ }^{2}$ com destaque para o de Tânia Elias Magno da Silva (1998), que analisa o acervo pessoal de Josué de Castro e sua vida desde a infância. “Descobri por suas próprias palavras que muito cedo, ainda menino, as imagens da fome haviam moldado os quadros que se fixaram em sua memória como um encantamento e geraram um estranho fascínio por estas imagens" (Silva, 2012, p.30). As pesquisas e publicações variam de escopo e perspectiva teórica, mas têm em comum, em maior ou menor grau, uma aceitação, baseando-se no discurso de Castro, da ideia de que a fome lhe teria surgido como tema em sua infância, o que lhe teria assegurado a vanguarda e o protagonismo nesse assunto ao longo de uma carreira linear.

Os trabalhos que questionam esse discurso, como o de Magalhães (1997) e o de Helder Amorim (2016), pautam-se em sua trajetória ou em sua filiação teórica para fazê-lo. Partindo de um posicionamento semelhante, o esforço deste artigo é contextualizar a obra de Castro a partir das representações de fome produzidas na época e, assim, passar a entendê-lo não como um agente individual da criação de uma temática, mas como parte de um processo de transformação do olhar social para o fenômeno da fome que se deu no Brasil em diversas frentes. 
Nesse sentido, a fome é vista como questão, e não como fenômeno. O foco aqui não serão as fontes essenciais para tratar a fome como fenômeno, como relatórios sobre crises climáticas, abastecimento ou flutuação de preço. As ocorrências são usadas para entender como ajudaram a fome a se tornar um tema debatido publicamente, mudando sua percepção. Essa temática foi paulatinamente construída no bojo de um conjunto de reflexões que incluiu outros pensadores que debatem sobre o tema da pobreza, fome e alimentação desde o fim do século XIX. A fome não é um produto do século XX, mas não era, contudo, objeto de estudo em proporções significativas antes dos anos 1930 e 1940 nem visto como um problema coletivo e estrutural. Por que se torna um tema aceito e amplamente discutido após essas décadas no Brasil?

As contestações das teorias raciais eugênicas e do Brasil como o país da abundância, somadas à consolidação do campo científico e educacional, trouxeram as questões alimentares para a ordem do dia. Se antes éramos atrasados por nossa miscigenação, agora a justificativa estava pautada nos problemas sociais, entre eles, a alimentação (Lima, Hochman, 1996). Esse novo olhar para o Brasil permeou o que este artigo nomeia espaço público letrado - jornais e revistas de grande circulação e obras literárias. Uma análise do modo como a fome foi inserida no bojo dessas discussões e passou a figurar em diferentes esferas de representações culturais nessas fontes nos dará compreensão mais detalhada do posicionamento de Josué de Castro em relação a elas e quais elementos ele agregou ao debate.

\section{Espaço público letrado e os retratos da fome}

O alargamento da noção de fome foi gestado em sucessivos discursos sobre a "realidade brasileira" - expressão normalmente associada a uma representação do país sem disfarce da miséria - veiculados na literatura, na imprensa e na ciência. Começar por esse espectro maior permite que vejamos em quais termos essa percepção se dava e quais tendências permitiram que a fome se tornasse um tema pertinente para a interpretação do Brasil em meados do século XX. Neste momento analisaremos a literatura e a imprensa de grande circulação.

A escolha das fontes se deu a partir das discussões propostas por Josué de Castro, autores que eram citados por ele ou com os quais ele se relacionava. Por isso, por vezes são citadas fontes anteriores ao recorte temporal, mas que influenciaram diretamente as discussões na primeira metade do século XX. Partindo-se desse princípio, não houve um recorte regional intencional. Contudo, as obras literárias acabaram por se concentrar no Nordeste, região de Josué de Castro. Nesse momento, ocorria a gestação da ideia de Nordeste. Muitas das produções desse grupo se pautaram na decadência da sociedade patriarcal retratando a miséria e a fome do povo com a intenção de traçar as diferenças em relação à realidade europeia, industrializada e que basearia o discurso do Sul e Sudeste (Albuquerque Jr., 2011, p.125-127).

Faz-se necessário, portanto, começar, ainda no século XIX, por uma seca avassaladora que dizimou metade da população e ocorreu no sertão nordestino, de 1877 a 1879, com epicentro no Ceará. Esse era o estado de Rodolfo Teófilo, que foi sua testemunha ocular. Além de ter ajudado muitos retirantes em Fortaleza, o farmacêutico também fez registros ricos de suas observações, com base nas quais escreveu alguns textos científicos e sua obra 
de ficção inaugural, $A$ fome, publicada em 1890. O livro não teve repercussão positiva na época, e muitos críticos se detiveram nos erros gramaticais que continha e na extrema crueza de suas descrições.

Baseado na vivência do autor, o livro narra a história de um retirante, Manuel de Freitas, que, apesar de ter terras no sertão do Ceará, perde tudo com a seca e migra para Fortaleza. "Poucos eram os que não estavam reduzidos à magreza extrema. No leito da estrada encontravam-se, a cada passo, ossos humanos, cuja pele seca e colada os conservava articulados" (Teófilo, 2011, p.47). Nesse caminho, o personagem presenciou cenas estarrecedoras, como um recém-nascido que mama na mãe morta, uma mulher devorada, ainda viva, por urubus, ou casos de canibalismo, incluindo crianças. Apesar de não ter sido um sucesso de vendas, o livro influenciou escritores do chamado Romance de 1930, como José Américo de Almeida, José Lins do Rego, Graciliano Ramos e Rachel de Queiroz, que serão aqui focalizados.

O próprio Josué de Castro (1948) dedicou seu livro Geografia da fome a Rodolfo Teófilo e Euclides da Cunha, "sociólogos das áreas de fome no Brasil". Nascido no Rio de Janeiro, em 1866, Cunha se formou em matemática e ciências físicas e começou a colaborar com alguns jornais quando foi enviado a Canudos com duas funções - jornalista e adido ao Estado-Maior do Ministério da Guerra. O acontecimento, que mais tarde constituirá o livro Os sertões, lançado em 1902, diz respeito à batalha entre os sertanejos de Canudos, uma comunidade que pregava autonomia da República, e o Exército brasileiro, travada de 1896 a 1897.

Por que Josué encara esse autor como o sociólogo da fome? Euclides da Cunha, apesar de não ter o tema da alimentação ou de suas carências como central, enxergou a fome quando estava falando sobre a Guerra de Canudos e fez uma interpretação sintética daquele cenário. Em carta enviada ao jornal O Estado de S.Paulo em 7 de agosto de 1897, enquanto cobria a guerra, Euclides diz (Cunha, 7 ago. 1897):

Em grande parte assediado, Canudos liga-se agora aos sertões que o aviventam apenas pela estrada do Cambaio; fechada esta última pelas forças que seguem, os sitiados cederão pela fome. E esta última já se faz sentir entre eles, em que pese a sobriedade espartana que os garante. Vivem, inanidos quase. Diversos soldados que inqueri afirmam - surpreendidos, que o jagunço degolado não verte uma xícara de sangue.

A fome também aparece quando Euclides narra as campanhas militares e diz que os soldados não estavam tão organizados: "A penúria de uns como prenúncios de fome condenavam à imobilidade a divisão em que se achava o principal chefe da campanha" (Cunha, 2002, p.224). Euclides teve um papel importante na constituição da imagem do sertão e do sertanejo por meio dessa publicação, pautando muitas das produções que vieram depois. Ele e Teófilo seriam pensadores importantes, aos olhos de Josué, para pensar o tema da fome no país. Ambos já haviam morrido no momento da dedicatória, 1946. Josué não estava buscando, portanto, uma aproximação ou ganho com esse ato, mas apontando o grupo que promovia os retratos da fome no qual ele queria se inserir.

Josué de Castro dedicou Geografia da fome, além de a Euclides da Cunha e Rodolfo Teófilo, também a "Rachel de Queiroz e José Américo de Almeida, autores de O quinze e A bagaceira, romances da fome no Brasil" (Castro, 1948). Rachel de Queiroz, escritora cearense, 
também abordou o sertão. Sobre o livro de Teófilo, teria dito que havia cadáveres demais, urubus demais. Ela, por sua vez, queria mostrar uma seca mais amena (Carvalho, s.d.). Seu romance de estreia, O quinze, lançado em 1930, aos 19 anos, narrava a seca de 1915 por meio de sua protagonista, Conceição, professora de Fortaleza que vai ao interior do estado para passar férias. Os dramas do desastre climático, da migração e da fome estão postos na dúvida dos personagens entre sair ou ficar no sertão. Chico Bento, vaqueiro que perdeu o trabalho na seca, decidiu ir - "Sem legume, sem serviço, sem meios de nenhuma espécie, não havia de ficar morrendo de fome, enquanto a seca durasse. Depois, o mundo é grande e no Amazonas sempre há borracha..." (Queiroz, 2012, p.30). Como não conseguiu ajuda do governo para fazer a travessia, fez o percurso a pé. O caminho até Fortaleza representa, na obra, a luta pela sobrevivência. "Só talvez por um milagre iam aguentando tanta fome, tanta sede, tanto sol. O comer era quando Deus fosse servido" (p.67). E, quando finalmente chegou à capital, foi para um campo de concentração para os retirantes, Alagadiço, onde a miséria e a fome não os deixaram. Por fim, Conceição comprou passagens para a família de Chico Bento se mudar para São Paulo, terra do dinheiro e do café. O romance teve ótima aceitação de público e crítica.

Um pouco antes, em 1928, um paraibano formado em direito, José Américo de Almeida, lançara A bagaceira. O livro começa pela seca de 1898 e termina com a de 1915 , e tem o enredo pautado pelo triângulo amoroso entre Soledade, retirante que chega à fazenda de Dagoberto Marçau, o senhor de engenho viúvo que inicia um caso com ela, e seu filho Lúcio, idealista, que mantém uma paixão não concretizada pela moça. É um romance da seca por trazer os retirantes aos engenhos de cana, que "chegavam mastigando em seco, para enganar a fome, nas mais grotescas atitudes da miséria" (Almeida, 2010, p.156). Mas também é um romance que trata dos problemas sociais dos engenhos, na Zona da Mata. Soledade foge para outra fazenda com Dagoberto, que acaba morrendo, deixando-lhe um filho. Na seca de 1915 a protagonista volta ao engenho Marzagão para entregar o irmão a Lúcio, que os aceita novamente. A publicação foi um sucesso e teve quatro edições só no primeiro ano, duas pela Imprensa Oficial da Paraíba e duas pela livraria Castilho. Os quatro autores aos quais Castro dedica seu livro não estavam no seu campo de formação, como veremos adiante, nem com eles travava um debate direto. Suas obras estavam pautadas nos problemas sociais da época e imprimiam o tema da fome por meio de tais questões e da temática sertaneja. Os livros, citados por Castro, expressavam uma ideia de como vivia parte da população brasileira e quais eram seus males. O sucesso de vendas e de crítica de três deles mostra como esse retrato tinha aderência entre o público leitor.

O que Teófilo apresentou não era exagero de uma ficção e estava também nos jornais durante as grandes secas no sertão nordestino. Em 1932, ano no qual Josué de Castro defendeu sua tese (O problema fisiológico da alimentação no Brasil) para ingresso na Faculdade de Medicina de Recife para lecionar fisiologia, igualmente aconteceu uma seca ímpar, uma das maiores que esse território enfrentou. Embora não ocupassem a primeira página, as notícias da aflição daquela população foram constantes na imprensa daquele ano. $\mathrm{O}$ conteúdo variava entre as mais simples menções à ausência de chuva, passando pelos saques e chegando a descrições precisas do que estava acontecendo nas regiões afetadas. Havia notícias como a do Correio da Manhã, que dizia: “O 'Diário de Notícias' lembra, 
a propósito, cena de canibalismo que se verificou na última seca, próximo a cidade de Juazeiro: alucinados pela sede, os pais de uma criancinha agonizante sangraram-na para chupar-lhe o sangue" (Os horrores..., 21 set. 1932, p.7). Essa não era uma notícia isolada na imprensa, como podemos ver nesse outro momento em que "uma pobre mãe, vendo seus filhos chorar à fome, num gesto de desespero, matou quatro deles" (O Nordeste..., 19 fev. 1932, p.3). Esse tipo de narrativa já vinha se tornando, desde o fim do século XIX, predominante na veiculação das notícias sobre a fome. Com a população sem as defesas corporais necessárias, as epidemias não eram raridade em áreas de fome. Jaguaribe, no interior do Ceará, por exemplo, teve um surto de paludismo em 1938. Ao longo da matéria sobre o surto, publicada pelo jornal Diário de Pernambuco, então o maior em circulação no Nordeste, o repórter narrava a visita à cidade que estava sofrendo com a doença. Lá se encontrava Lourenço Pereira, um dos afetados, que disse: “Toda a minha família morreu implorando o que comer. O único que ainda vive sou eu, e penso que não viverei mais por muitos dias. Tudo o que eu possuía, já vendi, inclusive as minhas alpergatas velhas, por 500 réis. Não tenho mais nada. Ninguém se importa comigo. Vejo pois que o meu caminho é a morte pela fome" (Com a população..., 30 maio 1938, p.4). A ausência de alimentos matava ora por inanição, ora por doenças associadas.

O modelo internacional da personificação da fome passa pela construção simbólica de um indivíduo - especialmente crianças e mulheres - entregue à própria sorte e sem meios para reagir a sua miséria. A fotografia foi um instrumento essencial para a aproximação da temática da fome com o leitor e a criação de uma sensibilidade ao tema por meio desses personagens. Elas mostravam crianças esqueléticas, com a barriga inchada, mulheres, principalmente mães, também muito magras, todos em condições precárias. Essa exposição traz um sentimento de horror e compaixão que é parte da expansão da pertinência da fome como questão. São personagens que dificilmente podem ser responsabilizados pela própria fome, fazendo com que esta ganhe uma dimensão além da responsabilidade individual (Vernon, 2007).

Eram constantes as menções à grande quantidade de retirantes que se deslocavam para o litoral, caminhando ou por trem, e que, no meio do caminho, quando podiam, furtavam algum boi que tivesse conseguido sobreviver à seca ou saqueavam mercados. No jornal O Povo aparecia a manchete: "Mais dois trens entulhados de famintos se dirigem a esta capital" (Mais dois..., 13 abr. 1932, p.1). Quando não conseguiam passagens de trem, que às vezes eram distribuídas pelo governo, os flagelados da seca invadiam ou saqueavam o meio de transporte. A narração nesses casos trazia uma empatia pelo famélico ou a justificativa pelos atos cometidos na conjuntura de escassez que não ocorreria se a mesma ação fizesse parte de um contexto distinto. Isso quer dizer que um saque a um armazém obtinha certa complacência da imprensa, dada a proporção do problema gerador do saque - a fome. O mesmo ato não teria tal entendimento se não fossem as circunstâncias que o geraram. Raciocínio semelhante é empregado em narrativas sobre os indivíduos afetados e suas histórias.

Os relatos de testemunhas oculares dos acontecimentos extremos de fome se mostraram fundamentais para a aproximação do público ao fato em si. Nesse sentido, a retirada da culpa individual da fome e um endereçamento coletivo não podem ser creditados aos estudos 
de Castro, e sim a uma mudança epistêmica maior que já estava posta nesse momento. A diferença está no olhar sobre a causa do problema, que era vista como um infortúnio climático ou pessoal e passa a ser tratada, depois da abordagem na qual Castro está inserido, como uma questão de base socialmente constituída. Cabe aqui ressaltar que a cobrança para a ação do Estado estava presente na imprensa como um aceno para tratar do problema, sem, no entanto, responsabilizá-lo pelas crises, que, nesse caso, ainda eram atribuídas a causas naturais: "Que os poderes públicos e as classes conservadoras da Bahia não fiquem inertes, impassíveis, ante o espetáculo pungente, que se desenrola pelo sertão de nossa terra. Urgem providências em favor dos infelizes flagelados do interior" (Os terríveis..., 3 maio 1933, p.7). O Estado era acionado como aquele que poderia solucionar o problema. A eficácia do governo era medida por sua capacidade de conter as crises de fome, exigência que se intensificou quando a política passou a ser também biopolítica. ${ }^{3}$

As ações estatais aconteciam. Havia a Inspetoria Federal de Obras Contra a Seca, que construía estradas e poços como possíveis soluções. Na tentativa de conter a horda de retirantes fugindo da fome na seca de 1932, o governo federal, na época sob o comando de Getúlio Vargas, com o apoio do interventor federal do Ceará, criou sete campos de concentração para reter essas pessoas. Uma vez ali dentro, a população não poderia mais sair e deveria obedecer às duras regras impostas pelos dirigentes indicados pelo interventor. O maior desses espaços, na cidade do Crato, chegou a abrigar quase 60 mil pessoas (Rios, 2014). "Em Fortaleza, apesar da sobrecarga de enorme população de adventícios, não se vê, entretanto, um só retirante nas ruas da cidade. Nos campos de concentração, os emigrantes são obrigados a se banhar, diariamente, a cortar os cabelos etc." (O Nordeste..., 26 abr. 1932, p.2). O cenário era diferente da Fortaleza que aparecera no romance de Rodolfo Teófilo, quando os famélicos perambulavam e ocupavam a capital do Ceará. Apesar de ser o estado mais atingido, não era, entretanto, o único. Notícias dão conta de situação similar em Pernambuco, Paraíba e Rio Grande do Norte. Importante ressaltar que o entendimento de fome como crise endereçava ações de contenção emergenciais como essas apresentadas. Dito de outra forma, se a fome não acontecia no curso cotidiano da sociedade, ela não precisava ser combatida nessa esfera. Foi justamente o alargamento do entendimento do que é fome e de quais são suas causas que trouxe uma série de organismos governamentais com políticas contínuas de combate à fome, como restaurantes populares, alimentação escolar e leis como a do salário-mínimo.

Castro se inscreveu nesse movimento de construção discursiva da fome, mas não de forma linear. Projetou um livro com Bezerra Coutinho sobre aclimatação do Nordeste que não se concretizou. Além disso, tinha grande interesse pela literatura. Seus primeiros escritos versavam sobre críticas literárias, cinema e teatro, não abordavam a temática da fome (Melo, 2011). É também sua atração por outras áreas além da fisiologia, sua atuação profissional inicial, que vai proporcionar ao autor um olhar mais amplo para as discussões em torno da alimentação.

Na primeira versão do livro Documentário do Nordeste, lançada em 1937, Castro compilou uma série de artigos seus sobre literatura. Neles, ele afirma que somente nesse período teria surgido, do Nordeste, "a primeira fornada de verdadeiros romancistas brasileiros", como José Lins do Rego, Jorge Amado, Jorge de Lima, José Américo, Rachel de Queiroz, Amando 
Fontes e Graciliano Ramos (Castro, 1937, p.72). Em suas palavras, a opção feita por essa corrente trazia um Brasil retratado de forma mais crua, como pobre, faminto e carente.

No mesmo estilo, os primeiros escritos ficcionais de Castro, os contos "O ciclo dos caranguejos" e "João Paulo", serão os embriões do que, mais tarde, será seu romance Homens e caranguejos, lançado em 1967. Eles narram a história de uma família retirante da seca que não se adaptou à Zona da Mata. Com os salários baixos e sem a possibilidade de plantar qualquer coisa, senão cana, foram para a cidade com a esperança de comer até matar a fome. "Mas a vida do operário era apertada como sempre. Muita coisa prôs olhos, pouca coisa prá barriga" (Castro, 1937, p.27). Com a impossibilidade de pagar qualquer aluguel, foram para o mangue. Lá as casas são feitas do barro do mangue, o mocambo, que também fornece alimento para as famílias, o caranguejo. Esse era o ciclo do caranguejo, que mantinha 100 mil pessoas.

Um ano depois de Documentário do Nordeste ser publicado, Graciliano Ramos, um dos citados por Castro, lançou Vidas secas, seu quarto romance, em 1938. O romancista alagoano, que havia estreado com Caetés, em 1933, narra a história da família de Fabiano, vaqueiro que, ao fugir da seca, encontra abrigo em uma fazenda pelo caminho. "Chegara naquele estado com a família morrendo de fome, comendo raízes" (Ramos, 2019, p.23). Por lá ficaria com sua esposa, dois filhos e a cachorra Baleia, até quando a seca os levaria, novamente, para a estrada. O paraíso que procuravam aparece sempre como expressão verbal, no condicional. O livro, com linguagem elaborada e enxuta, fez sucesso entre crítica e público.

O movimento literário da época, apesar de tratar dos dilemas sociais em suas diferentes facetas, estava mais preocupado com a fome gerada a partir de uma crise e dava menos espaço para a fome estrutural. É preciso ter em mente que as fronteiras que separam as categorias analíticas criadas para entender um fenômeno social nunca chegam a se formar plenamente, porque influências, trocas e entrelaçamentos são mais complexos que as divisões que damos a elas. Na tentativa de sistematização, procuramos olhar de longe e formar uma geometria na qual há o entrelaçamento de concepções. Não há, portanto, uma separação estanque dos diferentes entendimentos de fome, e os processos distintos que a formam podem estar contemplados em uma mesma obra. Essa geometria nunca se comprova plenamente quando colocada em confronto com aquilo que a forma. Ela é, porém, necessária, para que haja o entendimento inicial do que está sendo produzido naquele momento.

É o caso de José Américo de Almeida, que cunhou, em A bagaceira, a frase que se tornou emblemática: "Há uma miséria maior do que morrer de fome no deserto: é não ter o que comer na terra de Canaã" (Almeida, 2010, p.102). Quando acontecia a migração por causa da seca, a chegada à capital ou a terras menos afetadas não era sinônimo de alívio. No livro, João Troçulho, trabalhador da fazenda na Zona da Mata que é o palco do enredo, quando indagado por Lúcio sobre seu maior desejo, diz que é comer até matar a vontade. A diferença entre ele e os flagelados da seca é que João tinha trabalho, era cortador de cana, tinha morada, mas não tinha comida para matar a fome. Essa fome não era fruto de um descompasso climático ou de algum conflito, era permanente e algo inerente à posição social na qual João estava inserido. É essa fome que Castro vai chamar de endêmica em seu livro Geografia da fome. 
Se a fome epidêmica está relacionada a uma crise, não quer dizer que essa crise não se dê também no âmbito individual, quando, por exemplo, há o decesso social de um indivíduo ou de uma família. Nesse caso, a história do sujeito se funde a algo estrutural e condicionado ao lugar social, passando, então, a fome endêmica, já que é a nova condição social que vai limitar o acesso ao alimento. Essa questão está exposta em um personagem de Cacau, livro de Jorge Amado lançado em 1933 e também um dos escritores próximos a Castro. José Cordeiro, que é demitido da fazenda do tio em Sergipe e passa por uma série de privações, vai tentar a sorte em Ilhéus, terra do cacau, e quando chega não encontra trabalho. "Então comecei a sentir fome. Assim como uma legião de ratos a me roer o estômago. Uma coisa esquisita que me dava vontade de chorar e furtar ... não via mais Jesus. Via a fome. E a fome com os cabelos de Jesus e seus olhos suaves. ... Eu sorria confuso, quase com vergonha de ter fome" (Amado, 2010, p.45). Quando José encontra trabalho, o salário mal dá para se alimentar. Cada personagem no romance representa um nível social; a preocupação foi falar sobre a exploração dos trabalhadores e como estavam condicionados a essa posição. O primeiro de vários romances com engajamento marxista de Jorge Amado fez sucesso e alçou o autor internacionalmente.

Nos jornais, as secas e suas mazelas eram notícias, porém de forma menos intensa que a seca de 1932. Com o início da Segunda Guerra Mundial, em 1939, as notícias sobre fome voltaram a ser amplamente veiculadas. Quando o exército alemão de Hitler invadiu a França, o país começou a enfrentar problemas de abastecimento que eram intensificados pelo bloqueio inglês, e as notícias sobre as dificuldades de acesso ao alimento repercutiam. A situação se mostrava ainda mais crítica na Grécia. "Os franceses devoraram todo o estoque de forragem e nabos, comeram todos os corvos e pardais. Os habitantes do sul da França comem capim, que eles denominam salada Laval. Os do norte subsistem com cascas de árvore. Enlouquecidos pela fome, os gregos devoram arbustos. ... Não há mais cachorros, todos já foram devorados. ... Vários casos de canibalismo foram observados entre as crianças vadias da Grécia" (Ehrenburg, 11 maio 1944, p.14)

É em momentos de extrema escassez que o entendimento do que é alimento ou não se amplia ao máximo e entram animais dificilmente comestíveis na cultura ocidental contemporânea, como cães e gatos, além de plantas não apreciadas por serem alimentos de animais ou tóxicas, como mucunã e macambira. Mais uma vez, os casos de canibalismo apareciam como solução quando a vida era colocada em risco. Para algumas culturas, como a nossa, o canibalismo é a última barreira entre o que é ou não alimento, considerado um dos maiores tabus da cultura ocidental, junto com o incesto. ${ }^{4}$ A prática apareceu em situações distintas no século XX quando a vida foi posta à prova, como a fome na Rússia em 1920 ou na China entre 1958 e 1961. No caso da Segunda Guerra Mundial retratada pela imprensa brasileira, os testemunhos estavam tanto entre os civis quanto entre os militares. Uma cena de canibalismo foi relatada em Tóquio por soldados japoneses que se encontravam na ilha de Saipan, quando os americanos invadiram o país, ou dentro dos campos de concentração nazistas por um médico que estava entre os prisioneiros (Canibalismo..., 29 set. 1945, p.1).

A Segunda Guerra Mundial trouxe, além da imensa fome retratada nos territórios afetados, uma escassez significativa para outros lugares, a exemplo da América Latina. Se em 1941, momento em que tropas norte-americanas desembarcaram no Recife, havia uma quantidade 
razoável de alimento, o mesmo não pode ser dito com a intensificação da guerra (Toscano, 2019, p.485). Nas comemorações do Natal de 1944, surgiram na imprensa queixas da população sobre a falta de alimentos tradicionais da festa ou sobre os preços, principalmente no mercado negro - prática corriqueira, em maior ou menor grau, em épocas de racionamento. No caso brasileiro, a carestia era fruto mais de pessoas e mercadorias mobilizadas em torno da guerra do que do conflito em si. Ela não só ocasionou a exportação de recursos nacionais, como foi usada como justificativa para a especulação dos comerciantes. A alta dos preços é um entrave-base para o acesso da população mais carente ao alimento. Assim, enquanto os abastados se privavam de poucos itens ou nem isso, já que podiam encontrar no mercado paralelo, os que não tinham recursos se tornavam mais vulneráveis às flutuações.

Depois de declarado o fim da guerra, em 1945, ainda pululavam notícias de fome em um território que começava a tentar se restabelecer. O esforço de guerra tinha deixado uma situação grave de insegurança alimentar. Os jornais mostravam que milhões de pessoas estavam desalojadas e desempregadas e outros milhões sob o espectro da fome. Em países como Polônia, Itália, Grécia e Espanha, havia centenas de milhares de crianças famintas e descalças (As condições..., 1 jan. 1946, p.7). As notícias falavam em 150 milhões de europeus na iminência da fome. Dois terços recebiam menos de mil calorias por dia, e 25\% das crianças estavam morrendo.

A Segunda Guerra Mundial teve um papel fundamental na imprensa nacional para a constituição da fome como um tema pertinente. Em primeiro lugar, por sua magnitude, pois estima-se que pelo menos 20 milhões de pessoas tenham morrido de fome ou de doenças associadas em decorrência da guerra, quase a mesma cifra que a perda militar, que girou em torno de 19 milhões (Collingham, 2012). Em segundo lugar, por trazer o tema ao cotidiano do público letrado, pela quantidade de notícias produzidas com frequência nos jornais do país.

O fim da guerra marcou a intensificação da exposição dos problemas sociais no país. David Nasser, jornalista de grande repercussão na época, apontou para a crise do abastecimento de pão e outros gêneros alimentícios no Rio de Janeiro, na revista de maior circulação no país, O Cruzeiro: “Com a fome que aí está, a carência absoluta de alimentos, as longas filas de pão e de leite, a falta de elementos essenciais à alimentação, o Brasil está às vésperas da maior catástrofe nacional" (Nasser, 21 jan. 1946, p.34).

Não por acaso, em 1946, foram publicados dois livros com a palavra fome no nome: o primeiro, Fome de pão, de Adolfo Porto (1946), teve pouca repercussão, apesar de algumas críticas favoráveis. $\mathrm{O}$ autor, jornalista, de tradicional família pernambucana que havia se radicado no Rio de Janeiro, organizou uma coletânea de textos diversos que, apesar do título, não tem como tema central a fome. O segundo livro é Geografia da fome, que teria uma repercussão substancial não apenas para a carreira de seu autor, Josué de Castro, mas também na formulação do debate. Paradoxalmente, a guerra serviu como o elemento propulsor de combate à fome, pois, apesar de ser um fato causador, ela trouxe a questão para a ordem do dia e ocasionou a fundação de órgãos voltados para sua extinção, como a FAO, que nasceu nesse e desse contexto.

Os relatos aqui colocados têm em comum um elemento: são relacionados, principalmente, à fome epidêmica, nas palavras de Josué de Castro, uma fome que acontece por algum desvio 
do curso regular das coisas - fome derivada da crise. Se não por um desastre climático, como as secas, por uma guerra. De qualquer forma, ambas as situações são momentâneas e esvaziadas da condição estrutural na qual estão inseridas. A fome, portanto, aparece como uma fatalidade, elemento inevitável do curso dos acontecimentos. Suas magnitude e intensidade vão proporcionar o impacto para a temática e trazer a discussão para a ordem do dia.

A pobreza está presente na literatura e nas diferentes representações das classes populares brasileiras, e por ela a fome vai se enunciando timidamente como uma questão ligada à renda. Sua persistência e seu grau de ocorrência estão intimamente aderidos à condição social na qual o homem ou a mulher estão inseridos mesmo em uma crise. Nesse sentido, há uma grande ausência, na imprensa principalmente, das diferentes soluções alcançadas pelos distintos grupos sociais durante as crises de fome. Em uma seca aguda, o sertanejo com dinheiro conseguia fazer mais provisões ou migrar de forma mais confortável e rápida que o pobre. Este, em alguns casos, tinha que fazer o percurso a pé até alguma cidade do litoral, e poderia sucumbir no caminho. Chegando ao destino, não tinha nenhuma garantia de que sua fome seria saciada. Na iminência de uma guerra, as chances de uma família abastada se desvencilhar da zona de conflito eram maiores do que as das famílias sem recurso. Sem contar o mercado negro que se instalava a partir do fechamento ou congelamento do mercado oficial. Um dos poucos relatos que aparecem na imprensa tratava dos políticos fascistas.

Se tem notícia de que as classes ricas da Itália estão vivendo com uma prodigalidade imprópria destes tempos de guerra. Isto é certo especialmente entre os dirigentes do Parlamento Fascista, os quais, ao que parece, utilizam papel moeda para comprar numerosos artigos de luxo, nas chamadas 'bolsas negras', ou seja, mercados clandestinos, onde os preços em vigor são 7 ou 8 vezes mais elevados que os oficialmente fixados (Enquanto..., 9 abr. 1942, p.1).

Não era uma regra seguida à risca, mas era, certamente, a tendência. É preciso considerar que, mesmo na situação de fome epidêmica, causada por alguma situação anormal, a população não seria atingida de maneira uniforme. Essas nuanças sociais de resposta às crises estão mais bem postas nos romances do que na imprensa. O que aparecia menos nas representações de fome desse momento e que vai se tornar mais frequente a partir de então é que esse pobre, mesmo em situação cotidiana, na ausência de uma crise instaurada, também passava fome. Essa nova abordagem do Brasil pela chave da pobreza e o olhar para questões sociais que era gestado pela literatura podia ser vista também em outra base epistemológica da qual Castro fazia parte: a fisiologia e o surgimento da nutrição.

\section{A racionalização da alimentação}

A mudança na compreensão do fenômeno da fome ocorre no bojo do surgimento da modernidade, em que o discurso se baseia na noção de escassez. A forma de vida na modernidade ocidental - industrialização, urbanização, revoluções tecnológicas - tornou axiomático o fato de que a existência humana é a luta contra a escassez por causa dos recursos limitados existentes na natureza; enfim, a luta do homem contra a natureza, pela sobrevivência. Isso quer dizer que a noção que temos hoje de abundância, escassez e, consequentemente, fome 
se constituiu na modernidade. A mudança na compreensão de fome surgiu a partir de três fatores. O primeiro é o desenvolvimento e consolidação das ciências como conhecemos hoje, que, a partir das descobertas feitas de meados do século XIX até meados do XX dentro de uma mudança epistêmica maior, ${ }^{5}$ enquadraram o tema sobre o famélico dentro da modernidade. A alimentação e suas complicações viraram objeto da ciência.

O segundo motivo é a ligação entre fome e abastecimento de alimentos em termos de escassez. A óptica é cara a Thomas Malthus, um dos primeiros a estabelecer uma política econômica baseada no equilíbrio da escassez. Malthus, economista inglês que propôs a teoria na Europa do fim do século XVIII, achava que a fome era um mal necessário para a humanidade. Porque a população crescia em ritmo geométrico, e o alimento em ritmo aritmético, havia mais pessoas do que alimento, então a fome causava mortes para equilibrar esse descompasso. Malthus não previu, todavia, as revoluções tecnológicas e agrícolas que aumentaram a passos largos a produção de alimentos, sem, entretanto, acabar com a fome, mas desmoralizando sua interpretação.

O terceiro motivo é como a política se tornou biopolítica e passou a interferir nos corpos e em sua alimentação a partir desse novo caráter científico. O Estado passou a ser ator fundamental onde até então não era muito atuante: na formatação de formas ideais de alimentação, sua promoção e fiscalização a partir do entendimento de que existia um mínimo necessário para a manutenção da vida, o que vai levar ao estado de bem-estar social (Simmons, 2015).

Nesse contexto, a nutrição ganhou corpo e alguma sistematização quando profissionais de diferentes áreas, principalmente médicos e químicos, associaram o alimento à fisiologia animal em 1840. O primeiro passo foi dado por William Prout, em 1827, quando dividiu a composição do leite em sacarina, oleosa e albuminosa. Anos depois, porém, é lançado o livro tido como fundação da nutrição como ciência moderna - Animal chemistry, em 1842 (Kamminga, Cunningham, 1995, p.135). A partir desses estudos é possível analisar quantitativamente a ingestão de alimentos e a energia gasta pelo corpo para o trabalho e outras atividades, o que o historiador Levenstein (2003) chama de nova nutrição.

A nova perspectiva científica, portanto, forneceu uma ferramenta central para que Josué e seus pares pudessem olhar para a questão alimentar no Brasil - o paradigma calórico. No início do século XX, surgiu outro elemento para esse debate - as vitaminas. Pesquisadores perceberam que os alimentos não eram totalmente equivalentes e que a falta de alguns poderia provocar doenças. Assim, Casimir Funk, em 1912, deu o nome de "vitamine" a essas substâncias - "vital" mais "amine". Alguns anos depois, Jack Drummond mudou o termo para "vitamin", porque percebeu que essas substâncias não pertenciam ao grupo das aminas (Kamminga, Cunningham, 1995, p.235-259). As pesquisas relacionadas às vitaminas se desenvolveram principalmente nos EUA e na Inglaterra, e um de seus expoentes foi Frederick Gowland Hopkins, que montou a escola de bioquímica de Cambridge. Nesse contexto, ocorreu a segunda revolução da nutrição, chamada por Elmer McCollum de a mais nova nutrição (Biltekoff, 2012, p.177). Tais discussões foram intensificadas durante e após a Primeira Guerra Mundial. Com as dificuldades e as resistências dispostas no campo de batalha, a ingestão de alimentos se mostrou central para as estratégias nacionais. Atreladas a isso, as condições adversas impostas tanto à população civil como aos militares 
mostraram que a escassez de alimento poderia causar diversas doenças associadas. Assim, ocorreram mobilizações de diversos setores para o estudo do problema alimentar e muitos países criaram institutos voltados para essa temática - Inglaterra, França, EUA, Japão, Alemanha, entre outros. A chave alimentação entrou como possibilidade interpretativa dos desempenhos nacionais e de seus trabalhadores e, no caso brasileiro, reposicionou o debate sobre as raças (Lima, 2000).

Com esse cabedal científico, as pesquisas para quantificar e avaliar a alimentação das classes populares ganharam força na Europa no começo do século XX - a alimentação passou a ser passível de medição. Diversas organizações foram criadas no pós-guerra para combater os problemas de saúde, incluindo as questões relacionadas à nutrição. Entre elas pode-se citar a Organização de Saúde da Liga das Nações (League of Nations Health Organization) e a Organização Internacional do Trabalho (Muniz, 2019). O trabalho dessas organizações refinou as medições nutricionais para um programa de padronização, identificando os componentes de uma dieta saudável e determinando a quantidade necessária de consumo. O Brasil não estava alheio a esse cenário, como registrou Helion Póvoa (17 maio 1936, p.1), médico especialista em nutrição: "se outros méritos não possuísse a Liga das Nações, a ela, sobretudo, coube o melhor na urgente tarefa de sustentar desde 1925 que o problema alimentar das coletividades é uma das mais relevantes questões de higiene pública. Até então, o máximo dos esforços dos estudiosos da fisiologia dos alimentos era captado no sentido puramente clínico, casado em aplicações dietéticas as mais felizes".

Podem-se encontrar alguns trabalhos pontuais sobre o tema no Brasil ainda no século XIX, que não configuram, entretanto, uma corrente de estudos. É o caso de Manuel Gama Lobo, que, em 1865, aponta a má alimentação dos escravos como o motivo principal pelos problemas oftalmológicos. Outra análise importante para a temática é a desenvolvida por Rodolfo Teófilo, que, antes de seu romance Fome, publicou, em 1883, o livro História da seca do Ceará, 1887 a 1880, no qual analisa as consequências para o organismo da fome aguda causada pela grande seca sertaneja. Em 1908, Eduardo Magalhães lançou uma obra de maior fôlego, Higiene alimentar, que aborda problemas da alimentação brasileira a partir de um olhar clínico e dietético. No mesmo ano foram realizadas as pesquisas de Álvaro Osório de Almeida sobre alimentação e fisiologia. O assunto começou a ganhar protagonismo principalmente na área médica e, dentre os vinte temas escolhidos no primeiro Congresso Brasileiro de Higiene, em 1923, quatro tratavam da alimentação (Rodrigues, 2011, p.3738). Em 1932, Oscar de Souza publicou Fisiologia da alimentação, e, em 1933, foi criada a primeira cadeira de Nutrição na Faculdade de Medicina da Universidade do Distrito Federal, ministrada por Anne Dias (Brasil, 2010).

Essas novas ferramentas foram essenciais para a mudança da compreensão que estava sendo gestada sobre o entendimento da fome. Sem elas, não haveria a medição qualitativa e quantitativa do que era ingerido. Naquele momento começam a surgir termos como subnutrição ou má nutrição para designar problemas relacionados à alimentação.

Em 1932, Josué de Castro defendeu sua tese O problema fisiológico da alimentação no Brasil, para se tornar professor de Fisiologia na Faculdade de Medicina do Recife. Mas, quando a transformou em livro, o título perdeu o termo fisiológico e saiu apenas como O problema da alimentação no Brasil (Castro, 1939). A supressão do termo nos dá uma pista de como vai se 
dando a guinada para o olhar social de Castro. Entre a tese e o livro, em 1933, Castro fez um estágio com Pedro Escudero, considerado um dos pioneiros na América Latina entre os que vincularam a nutrição a questões sociais da alimentação. Escudero fundou o Instituto de Nutrição de Buenos Aires, em 1926, e criou a Escola Municipal de Dietistas, em 1933, que ganhou status universitário e passou a chamar-se Instituto Nacional de La Nutrición em 1938, tendo recebido inúmeros brasileiros (Buschini, 2016). A visão social de Escudero se faz sentir no prefácio que escreveu para o livro de Castro: "Não acreditamos que a determinação do metabolismo regional mereça atenção prática; o estudo da ração alimentar do homem em suas diferentes idades, condições de vida e demandas de trabalho interessa muito mais, e isso será determinado não nos laboratórios de fisiologia, mas nos refeitórios e cozinhas de fábricas, asilos e hospitais e nas casas do homem modesto" (Castro, 1939, p.XVII).

Ora, o tema central da tese de Castro era metabolismos basais em climas diferentes a partir de testes em laboratório. A pesquisa de Castro vai paulatinamente ganhando contornos sociais, com seu desenvolvimento mais acabado em Geografia da fome. A obra de Pedro Escudero teve profunda influência também em outros estudiosos como Heitor Anne Dias, Thales de Azevedo, Ruy Coutinho, Thalino Botelho, Peregrino Jr., Seabra Velloso, Helion Póvoa e Orlando Parahym.

Durante as décadas de 1930 e 1940, pode-se identificar outro grande grupo que pensava alimentação. A partir de uma perspectiva individual e biológica, esse grupo estava preocupado principalmente com os aspectos de ingestão e clínico-fisiológicos. Aqui podemos citar Paulo Santos, Silva Mello, Olavo Rocha, Alexandre Moscoso, Franklin de Moura Campos, Dutra de Oliveira e Dante Costa, profissionais influenciados por escolas norte-americanas e europeias de dietética (Vasconcelos, 2002).

Tais abordagens não tinham uma clara divisão, e, mesmo com bases diferentes, as obras concordavam que a alimentação do brasileiro era inadequada, quantitativa e qualitativamente, com excesso de carboidratos simples e falta de vitaminas e minerais, presentes no leite, em ovos, verduras, legumes e frutas, que a população não consumia ${ }^{6} \mathrm{Com}$ esse horizonte, a fisiologia torna-se uma categoria analítica essencial para a interpretação da sociedade e sua alimentação. Mesclada à ideia de evolução, suas ferramentas eram usadas para mostrar o caminho para o progresso por meio do entendimento da alimentação humana.

Os inquéritos higienistas - aqueles que pretendiam olhar os hábitos do povo para os adequar aos preceitos modernos - começaram a surgir no Brasil desde o início do século XX, ainda que sem pretensões estatísticas. Pode-se citar o coordenado por Arthur Neiva e Belisário Penna em 1912, para pesquisar as condições de saúde da população pelos sertões de Pernambuco, Piauí e Goiás. Com viés mais estatístico, mas sem precisão, há os trabalhos de Carlos Sá ou o de Ruy Coutinho, ambos os autores tratando, em 1931, de regimes alimentares em alguns estabelecimentos escolares do Rio de Janeiro (Coutinho, 1937).

Na década de 1930 tais pesquisas ganharam importância e sistematização, como a feita por Josué de Castro em 1934 em bairros operários do Recife, publicada em As condições de vida das classes operárias no Nordeste. Apesar de o próprio Josué dizer que fez esse inquérito em $1932^{7}$ e essa data ser assumida pelas pesquisas que se debruçam sobre o autor (Silva, 2016, p.27), outras fontes apontam que o inquérito foi realizado em 1934. Em 
A alimentação brasileira à luz da geografia humana, lançado em 1937, ele afirmou que teria feito o trabalho sobre a população pobre de Recife em 1934: "Preocupados, há vários anos, com o problema da alimentação no Brasil, procedemos em 1934, a um inquérito sobre as condições alimentares das classes operárias de Recife" (Castro, 1937, p.134.). Além disso, não há notícia na imprensa sobre o inquérito antes de 1934. Essa perspectiva cronológica é revelante, pois a ordem dos fatos se reflete em sua obra. Há, entre a tese e esse trabalho, uma diferença metodológica e argumentativa significativa, o que mostra que o início do uso das categorias analíticas da pesquisa quantitativa com os operários de Recife ocorreu entre a tese e o inquérito alimentar. Sendo As condições de vida das classes operárias de Recife de 1934, podemos supor que a estada de Castro com Pedro Escudero em 1933 foi um dos elementos centrais de sua mudança interpretativa. Com isso, também podemos assumir a não linearidade de seu trabalho e diminuir o peso de sua trajetória pessoal para a constituição da temática da fome, aumentando, portanto, o peso que têm as interpretações do espaço público letrado para a constituição da temática.

Nesse trabalho, o autor trouxe uma contribuição importante para o debate pelo recorte que fez de seu objeto: bairros proletários do Recife. Castro conseguiu enxergar as carências alimentares das classes populares, chegando à conclusão de que o consumo médio de calorias era de 1.645, enquanto o indicado para a época era de três a quatro mil. O deslocamento do problema da alimentação da seara fisiológica para a esfera social e econômica - tratando principalmente de desigualdade social - é a grande bandeira de Castro iniciada por essa pesquisa. Aqui ele diz: "Qualquer pessoa que possua noções gerais de dietética e diante de um regime desta ordem, só tem uma pergunta a formular: 'Como se pode comer assim e não morrer de fome'? E só há uma resposta a dar, se bem que um tanto desconcertante: 'Como? Morrendo de fome'” (Castro, 1959, p.87).

Mas ele não foi o único a fazer inquéritos alimentares. Cabe mencionar a pesquisa promovida pelo Instituto de Higiene de São Paulo. Feita por Geraldo Horácio de Paula Souza em parceria com Ulhôa Cintra e Pedro Egídio de Carvalho, entre 1932 e 1933, com 491 famílias de um bairro da cidade de São Paulo e publicada em 1935, ela diz que é preciso contrapor a ideia de que não há fome no Brasil, "principalmente no concernente à fome qualitativa, ou seja, de determinados alimentos. Somente inquéritos bem conduzidos e múltiplos, atingindo os mais diversos grupos sociais, e em diferentes pontos do país, poderão traduzir aproximadamente a realidade da situação" (Sousa, Cintra, Carvalho, 1935, p.4). A chamada para outros inquéritos foi, em certa medida, atendida, e houve um crescimento significativo deles nesse período. Com público-alvo distinto, tais pesquisas corroboraram a visão proposta por Geraldo de Paula Sousa e mostraram, de forma geral, que o brasileiro não se alimentava apropriadamente, às vezes qualitativamente - faltavam-lhe nutrientes -, às vezes quantitativamente - faltavam-lhe calorias.

Naquele momento, as carências alimentares do Brasil já eram tema consagrado pela imprensa e por especialistas. Castro conquistou um papel de destaque, bebendo nos estudos nacionais e principalmente internacionais sobre alimentação, pobreza e nutrição para debater a fome junto com outros intelectuais da época. A partir dos estudos científicos da época, ele começou a traçar, paulatinamente, o conceito que mais tarde, em Geografia da fome, chamará de fome endêmica. Nessa obra, ele dividiu o Brasil em cinco regiões e as nomeou 
áreas de fome endêmica, epidêmica ou de subnutrição. Por fome epidêmica ele compreendia episódios graves, mas momentâneos, que assolam um lugar, crises de fome. Por exemplo, a área nomeada por ele como sertão nordestino é considerada zona de fome epidêmica porque, nos momentos de chuva, a terra pode fornecer os alimentos necessários àquela população. É diferente da fome endêmica, que não está circunscrita a um acontecimento climático ou momentâneo e permanece no tempo, como ele assinalou ocorrer na área do Nordeste açucareiro. Pode-se notá-la na população carente das periferias que, sem renda suficiente para o sustento minimamente digno da família, compra uma quantidade inferior tanto quantitativamente quanto qualitativamente de alimento (Castro, 1948).

Há em Geografia da fome uma guinada terminológica importante feita por Castro: o que antes era subnutrição e carências alimentares passa a ser também denominado fome. Assim, fome passa a ser entendida como a falta de alimentos necessários para a reposição de energia e nutrientes gastos no desenvolvimento das atividades diárias por um grupo de pessoas em um período prolongado até o momento em que a vida é colocada em risco, mesmo que não seja por inanição. Ele argumenta que aquelas situações de crises de fome, que eram tão noticiadas na imprensa, precisam estar ao lado também da fome cotidiana, estrutural, que, por não estar associada a uma crise, passa despercebida. Inúmeros fatores se conjugaram para que sua obra se tornasse possível - novas ferramentas científicas, a influência de alguns atores, como Pedro Escudero, sua penetração na imprensa nacional, seu capital social adquirido e o cenário de produção letrada que versava sobre o tema. Foi então viável que ele se consagrasse como aquele que lançou luz à fome como fenômeno biológico de um problema social.

\section{Considerações finais}

As análises que se voltavam para as condições de vida da população a partir de uma abordagem fisiológica tinham convergência discursiva com visões de cunho social ou produções literárias do período, que propunham um olhar para o cotidiano da população. A partir das ferramentas científicas mencionadas e da grande massa de formadores de opinião que, mesmo sem estarem necessariamente ligados ao mundo científico, influenciavam o que se pensava sobre a fome no país, ocorreu uma paulatina reinterpretação do fenômeno da fome no Brasil na primeira metade do século XX.

A literatura e a imprensa tiveram papel fundante na exibição da fome, principalmente a partir das secas e da Segunda Guerra Mundial. Josué de Castro, que ganhou notoriedade nacional durante a década de 1930 com estudos relacionados à alimentação, na década de 1940 uniu a temática das crises de fome com os debates científicos em torno da alimentação da época por meio dos termos "fome endêmica" e "fome epidêmica", muito bem sistematizados no livro Geografia da fome. Dessa forma, Castro se vale da urgência do tema pela intensidade apontada no espaço público letrado no Brasil e das descobertas científicas feitas internacionalmente naquele momento.

Essa diferenciação começou a ser esboçada com o conceito de fome parcial, apresentado em seu livro Alimentação e raça (Castro, 1936), e se tornou central nas análises posteriores do autor. Sendo a fome também parcial, cotidiana, ela não estaria necessária ou exclusivamente 
associada às catástrofes naturais, não seria, portanto, uma crise, e sim um problema estrutural. Essa foi a guinada essencial da compreensão da fome no seu tempo - o vínculo entre fome e renda.

As categorias propostas por Castro são úteis no entendimento da percepção do fenômeno no Brasil, pois é justamente a acepção do que se compreendia por fome que vai se transformar a partir das discussões postas nesse momento. A fome vai se colocando no cenário por intelectuais, literatos, artistas e políticos como, principalmente, fome epidêmica, no bojo de outras grandes problemáticas. Essa fome não tinha, naquele momento, o título de fome epidêmica. O que eles entendiam por fome, pura e simplesmente, é o que foi identificado aqui como fome epidêmica ou crises de fome.

Castro fazia parte do grupo científico que estava articulando a racionalização da alimentação. Sua contribuição, nesse sentido, foi olhar para essa nova forma de medir a eficácia da ingestão de alimentos e associá-la de forma mais contundente às crises alimentares. As denominações atribuídas aos problemas alimentares da população eram má nutrição, subnutrição e insuficiência calórica, nutricional ou proteica. Ele vai dizer que a carência alimentar estrutural da sociedade também é fome - fome endêmica. Essa proposta de Castro foi um elemento importante para que Geografia da fome e ele ganhassem tamanha notoriedade. Quando a fome vai se impondo como problema político, portanto coletivo, ela está intimamente associada a episódios críticos. Castro empresta à fome uma condição estruturante de forma mais evidente do que estava posto na época. O sucesso da proposta foi imediato e estrondoso porque o tema já estava colocado em outros termos. A obra o colocou no debate internacional, mostrando a pertinência do debate proposto para o período.

Josué de Castro, que tinha ampla circulação entre os literatos e cientistas da época, percebeu esse processo, ao qual deu uma formulação própria. Ele não apresentou uma grande novidade metodológica para a época, e, sim, inscreveu-se na mudança epistemológica. Com o passar do tempo e valendo-se de seu posicionamento internacional como brasileiro, ele vai criando uma narrativa linear de sua produção que acaba sendo reverberada, apagando o debate no qual estava inserido: "O tema deste livro é a história da descoberta que da fome fiz nos meus anos de infância, nos alagados da cidade do Recife, onde convivi com os afogados deste mar de miséria. Procuro mostrar neste livro de ficção que não foi na Sorbonne nem em qualquer outra universidade sábia que travei conhecimento com o fenômeno da fome" (Castro, 1967, p.12).

$\mathrm{O}$ que Castro renomeou, mais tarde sendo reverberado por outros autores, como Amartya Sen, mesmo sem o citar, é que a fome não era meramente uma questão técnica de abastecimento ou advinda somente de problemas naturais. Ela passa a ser entendida também como uma questão de propriedade dos alimentos, um problema socialmente constituído que está relacionado ao lugar social ao qual pertence determinado grupo. Nesse sentido, a fome passa a ser encarada por quem assim a interpreta como um produto do conjunto de relações sociais e econômicas, portanto também históricas, daquele grupo. A partir daí, Josué de Castro intensificou o debate público e radicalizou suas propostas, como o apoio à reforma agrária e às ligas camponesas, posições que o fizeram exilado político depois do golpe civil-militar de 1964, em Paris, de onde nunca mais voltou. 


\section{NOTAS}

${ }^{1} \mathrm{O}$ significado de crise não é claro, pois o termo pode ser aplicado em situações distintas, de curta ou longa duração, com diferentes escopos. Aqui, trato crise especificamente como um grave desequilíbrio conjuntural em determinado espaço geográfico e temporal. Sobre o termo crise, sua acepção moderna e sua aplicabilidade aos estudos sobre a fome, ver Silva (2017).

${ }^{2}$ Para uma consulta do que foi produzido sobre Josué de Castro, ver o trabalho de Silva (2016).

${ }^{3}$ O conceito de biopolítica é caro a Michel Foucault (2008) e trata do controle político sobre os processos biológicos e do cotidiano humano, como os corpos e a saúde. Tal controle apareceu a partir do século XVIII no Ocidente e marca, desde então, a entrada da vida e de seus mecanismos nos cálculos racionais.

${ }^{4} \mathrm{O}$ canibalismo de sobrevivência, em consequência de uma crise de fome intensa, é um grande tabu para a cultura ocidental, mas há relatos dele em diferentes momentos da história. É diferente do canibalismo ritualizado e incorporado à cultura de determinada sociedade, chamado por Jared Diamond (2000) de canibalismo habitual. O que tratamos aqui acontece em momentos de exceção, quando a vida é colocada à prova pela carestia de alimentos. O tema já foi analisado em alguns trabalhos, como no artigo clássico de Pierre Bonnassie (1989) ou no livro de Cormac Ó Gráda (2015).

${ }^{5}$ Foucault e outros autores identificam, na virada do século XVIII e principalmente no século XIX, uma série de mudanças epistêmicas que são cruciais para o surgimento das ciências, inclusive humanas, como as disciplinas como conhecemos hoje. O resultado é o que ele chama de episteme moderna (Foucault, 2007).

${ }^{6}$ Nota-se que o padrão ideal de alimentação é essencialmente europeu. Sendo europeias as obras iniciais de referência, os primeiros trabalhos pautam o horizonte alimentar a partir dos pressupostos adotados além-mar. Até então, ignoravam-se quase por completo saberes e ingredientes nativos, elementos que ganharão força nos estudos posteriores.

${ }^{7}$ Essa data aparece em uma nota de rodapé do texto que foi incluído na segunda edição do livro Documentário do Nordeste: "Este estudo foi levado a efeito em 1932 na cidade do Recife" (Castro, 1959, p.75).

\section{REFERÊNCIAS}

ALBUQUERQUE JR., Durval Muniz. A invenção do Nordeste e outras artes. São Paulo: Cortez, 2011.

ALMEIDA, José Américo de. A bagaceira. Rio de Janeiro: José Olympio, 2010.

AMADO, Jorge. Cacau. São Paulo: Companhia das Letras, 2010.

AMORIM, Helder Remigio de. "Um pequeno pedaço do incomensurável": a trajetória política e intelectual de Josué de Castro. Tese (Doutorado em História) - Universidade Federal de Pernambuco, Recife, 2016.

AS CONDIÇÕES de vários países europeus. Jornal do Brasil, p.7, 1 jan. 1946.

BILTEKOFF, Charlotte. Critical nutrition studies. In: Pilcher, Jeffrey (ed.). The Oxford handbook of food history. Oxford: Oxford University Press, 2012.

BONNASSIE, Pierre. Consommation d'aliments immondes et cannibalisme de survie dans l'Occident du haut Moyen Âge. Annales: Économies, Sociétés, Civilisations, ano 44, n.5, p.1035-1056, 1989.

BRASIL. Ministério do Desenvolvimento Social e Combate à Fome. Fome zero: uma história brasileira. Brasília: Ministério do Desenvolvimento Social e Combate à Fome, 2010.

BUSCHINI, José. La alimentación como problema científico y objeto de políticas públicas en la Argentina: Pedro Escudero y el Instituto Nacional de la Nutrición, 1928-1946. Apuntes, n.79, v.43, p.129-156, 2016.

CANIBALISMO em Belsen. Correio da Manhã, p.1, 29 set. 1945.

CARVALHO, José Murilo de. Discurso para a posse da Academia Brasileira de Letras, s.d. Disponível em: http://www.academia.org.br/ academicos/jose-murilo-de-carvalho/discursode-posse. Acesso em: 10 maio 2019.

CASTRO, Josué de. Homens e caranguejos. São Paulo: Brasiliense, 1967.

CASTRO, Josué de. Documentário do Nordeste. Rio de Janeiro: José Olympio, 1959.

CASTRO, Josué de. Geografia da fome. São Paulo: Brasiliense, 1948.

CASTRO, Josué de. O problema da alimentação no Brasil. Rio de Janeiro: Companhia Editora Nacional, 1939. 
CASTRO, Josué de. A alimentação brasileira à luz da geografia humana. Porto Alegre: Edições Globo, 1937.

CASTRO, Josué de. Alimentação e raça. Rio de Janeiro: Civilização Brasileira, 1936.

COLLINGHAM, Lizzie. The taste of war: World War II and the battle for food. New York: The Penguin Press, 2012.

COM A POPULAÇÃO sem as defesas corporais... Diário de Pernambuco, p.4, 30 maio 1938.

COUTINHO, Ruy. Valor social da alimentação. Rio de Janeiro: Editora Biblioteca de Divulgação Científica, 1937.

CUNHA, Euclides da. Os sertões. São Paulo: Nova Cultura, 2002.

CUNHA, Euclides da. Carta. O Estado de S. Paulo, 7 ago. 1897. Disponível em: http://acervo.estadao. com.br/noticias/acervo,canudos-diario-de-umaexpedicao-euclides-da-cunha-781897,11951,0.htm. Acesso em: 5 dez. 2018.

DEVEREUX, Stephen. Theories of famine. New York: Harvester Wheatsheaf, 1993.

DIAMOND, Jared. Talk of cannibalism. Nature, n.407, p. 25-26, 2000.

EHRENBURG, Ilya. Os habitantes do sul da França comem capim. Diário de Pernambuco, p.14, 11 maio 1944.

ENQUANTO o povo curte fome, os chefes do Fascio gozam boa vida. O Jornal, p.1, 9 abr. 1942.

FOUCAULT, Michel. O nascimento da biopolítica. São Paulo: Martins Fontes, 2008.

FOUCAULT, Michel. As palavras e as coisas: uma arqueologia das ciências humanas. São Paulo: Martins Fontes, 2007.

HOWE, Paul; DEVEREUX, Stephen. Famine intensity and magnitude scales: a proposal for an instrumental definition of famine. Disasters, v.24, n.4, p.353-372, 2004.

KAMMINGA, Harmke; CUNNINGHAM, Andrew. Science and culture of nutrition, 18401940. Amsterdam: Rodopi, 1995.

KENEALLY, Thomas. Three famines. New York: Public Affairs, 2011.

LEVENSTEIN, Harvey. Revolution at the table. The transformation of the American diet. Berkeley: University of California Press, 2003.

LIMA, Eronides da Silva. Mal de fome e não mal de raça: gênese, constituição e ação política da educação alimentar no Brasil, 1934-1946. Rio de Janeiro: Editora Fiocruz, 2000.
LIMA, Nísia Trindade; HOCHMAN, Gilberto. Condenado pela raça, absolvido pela medicina: o Brasil descoberto pelo movimento sanitarista da Primeira República. In: Maio, Marcos Chor; Santos, Ricardo Ventura (org.). Raça, ciência e sociedade. Rio de Janeiro: Editora Fiocruz, 1996.

MAGALHÃES, Rosana. Fome: uma (re)leitura de Josué de Castro. Rio de Janeiro: Editora Fiocruz, 1997.

MAIS DOIS trens entulhados de famintos se dirigem a esta capital. O Povo, p.1, 13 abr. 1932.

MELO, Normando Jorge de Albuquerque. Josué de Castro antes da fome. Aurora, v.7, p.140-152, 2011.

MUNIZ, Érico. A construção de um modelo alimentar para a América Latina. Revista Ingesta, v.1, n.1, p.68-81, 2019.

NASSER, David. Brasil, campeão da tuberculose. O Cruzeiro, p.34, 21 jan. 1946.

Ó GRÁDA, Cormac. Eating people is wrong: and other essays of famine, its past, and its future. Princeton: Princeton University Press, 2015.

O NORDESTE trágico. A Noite, p.2, 26 abr. 1932. O NORDESTE trágico! A Noite, p.3. 19 fev. 1932. OS HORRORES da seca. Correio da Manhã, p.7, 21 set. 1932.

OS TERRÍVEIS efeitos da seca no sertão baiano. Correio da Manhã, p.7, 3 maio 1933.

PORTO, Adolfo. Fome de pão. Rio de Janeiro: Jornal do Brasil, 1946.

PÓVOA, Helion. A questão alimentar no Brasil. Diário Carioca, p.1, 17 maio 1936.

QUEIROZ, Rachel de. O quinze. Rio de Janeiro: José Olympio, 2012.

RAMOS, Graciliano. Vidas secas. Rio de Janeiro: Record, 2019.

RIOS, Kênia Sousa. Isolamento e poder: Fortaleza e os campos de concentração na Seca de 1932. Fortaleza: Imprensa Universitária, 2014.

RODRIGUES, Jaime. Alimentação, vida material e privacidade: uma história social de trabalhadores em São Paulo nas décadas de 1920 a 1960. São Paulo: Alameda, 2011.

SILVA, Marcelo Cândido da. Crise e fome na Alta Idade Média: o exemplo dos capitulários carolíngios. Anos 90, v.24, n.45, p.185-207, 2017.

SILVA, Mercês de Fátima dos Santos. Josué de Castro: um autor do legado esquecido? Tese (Doutorado em Ciências Médicas) - Universidade Estadual de Campinas, Campinas, 2016. 
SILVA, Tânia Elias Magno da (org.). Memória do saber: Josué de Castro. Rio de Janeiro: Fundação Miguel de Cervantes, 2012.

SILVA, Tânia Elias Magno da. Josué de Castro: para uma poética da fome. Tese (Doutorado em Ciências Sociais) - Pontifícia Universidade Católica de São Paulo, São Paulo, 1998.

SIMMONS, Dana. Vital minimum: need, science, and politics in modern France. Chicago: The University of Chicago Press, 2015.

SOUSA, Geraldo de Paula; CINTRA, Ulhôa; CARVALHO, Pedro E. Inquérito sobre alimentação popular em um bairro de São Paulo. Boletim do Instituto de Higiene de São Paulo, n.58, p.3-66, 1935.
TEÓFILO, Rodolfo. A fome: cenas da seca do Ceará. São Paulo: Tordesilhas, 2011.

TOBELEM, Alain. Josué de Castro e a descoberta da fome. Rio de Janeiro: Leitura, 1974.

TOSCANO, Frederico de Oliveira. Yes, nós temos Coca-Cola: o ideal da fartura norte-americana na mesa do Nordeste (1930-1964). Tese (Doutorado em História Social) - Universidade de São Paulo, São Paulo, 2019.

VASCONCELOS, Francisco de A.G. O nutricionista no Brasil: uma análise histórica. Revista de Nutrição, v.15, n.2, p.127-138, 2002.

VERNON, James. Hunger, a modern history. Cambridge, MS: Harvard University Press, 2007.

\section{$\rightarrow \rightarrow \rightarrow<<<$}

